\title{
Unpredictable and significant variability of rainfall: carryover stocks of water and food necessary
}

\author{
Jan Lundqvist
}

Published online: 29 July 2009

(C) Springer Science+Business Media B.V. 2009

\section{There is no such thing as an average}

For the world's farmers and for society at large, there is no such thing as an average availability of water. Rainfall patterns vary significantly, even over short distances and over time. The fluctuations are most severely experienced in semi-arid and arid parts of the world with a high potential evapotranspiration, i.e. in areas where water shortages recur. Differences in the amount of precipitation from one season or year to another typically vary one or a couple of times above or below an imaginary average. Millions and millions of small and poor farmers toil under a burning sun with few sophisticated inputs and implements, uncertainties and risks of cultivation are real, yields are generally low and the rate of undernourishment is high. Naturally, agricultural droughts, i.e. moisture deficits in the root zone during the season are not the only challenge. But it is interesting to note that a number of studies illuminate that the Gross Domestic Product, GDP, of countries with a large agricultural sector, e.g. in Africa, strongly co-varies with the variation in rainfall.

In this article an attempt is made to show that the performance associated with conventional approaches to deal with rainfall variability need to be revisited in view of the high social and financial costs. A mix of

J. Lundqvist $(\square)$

Stockholm International Water Institute, Stockholm, Sweden

e-mail: Jan.Lundqvist@siwi.org strategies that aim at building carry-over stocks of water and food from the fat to the lean years are urgently needed. These must be implemented in an increasingly competitive context embedded in climate change.

\section{Conventional approaches}

The risks related to the climatic variations have conventionally been tackled by building of storage facilities for water supplies. A surge of dam and reservoir construction was strong after the introduction of the Green Revolution, with a peak in the 1970s. A primary objective has been to cater for the seasonal water requirements in agriculture. Gradually, other sectors and interests have claimed increased provisions or alternative regulation and these compete successfully for a share of the water. Dams and reservoirs remain an important strategy to deal with a variable rainfall. Some would think 'What else can be done to cushion against the vagaries of an unpredictable climate'? However, when storage capacity in a basin is expanded, the performance and dependability may diminish while cost will escalate and sophistication of management needs to be enhanced. Inflow of water largely depends on the rains. If the rains in the catchment fail, and particularly if they fail for a number of consecutive years, aggregate storage capacity is not utilized and water deliveries from the reservoirs will also fail to a certain degree. 
In a detailed account of the water resources situation in the Bhavani basin in southern India, Lannerstad (2009) shows that the reservoir storage capacity and size of command area is often in excess of water inflow. Political signals in countries all over the world have underscored this development and liberal credit schemes have made this development possible. The perception of Mr. Jawaharlal Nehru, the first Prime Minister of Independent India, from 1947 to 1964 , of "dams as the temples of Modern India" refers to a famous statement that he made at the end of his reign, in October 1963.

Apart from political visions and a 'privileged treatment' in budget negotiations other drivers for dam construction are at work. Farmers invariably push for more water, increased size of command area and other interest groups demand increased supply to rapidly growing urban centers.

In sub-Saharan Africa, storage is still quite low and less than $5 \%$ of the agricultural land is irrigated. Due to extremely high investment costs, poor performance of existing schemes, environmental and other concerns, conventional storage will most probably not play a major role in agricultural development.

An estimated 1.2-1.4 billion people, i.e. about 20\% of the world's inhabitants live in basins where the water flow in rivers is already highly exploited and committed to various users to the extent that the basins are deemed "closed" for further exploitation. This does, however, not mean that the entire water resource in the basin is beneficially used as discussed below.

\section{A new era of water related development predicaments}

A continuous increase in world population means that the need and demand for food and other goods and services is increasing. Importantly, the shift in the composition towards a larger fraction of water intensive food items, amplifies the water requirements. This trend is parallel with a rapid urbanization. Many people and interest groups have the economic means and/or the political clout to claim a growing share of the water for the benefit of household, industrial or service sectors and the environment. Consequently, the water readily available for food and agricultural production will decrease while the expectations are high that food supply will improve, notably at low prices for the consumers with an associated low pay to the producers.

Predictions by the International Panel of Climate Change, IPCC, tell us that we should prepare for a higher frequency of extreme weather events. Irregularities of the monsoon, e.g. in Asian countries and prolonged periods of reduced rainfall in Africa have repeatedly caused droughts but also floods, mass hunger and destitution. Now, reports about potential massive out-migration from degraded lands are common. Lannerstad (2009) compiled information of incidences of failures of the monsoon and the human sufferings in southern India during a hundred year period from the beginning of the ninetieth century. "..scarcity, desolation and disease" were rampant at eighteen occasions with a duration of one or a couple of consecutive years. For individual years, like 1808, failure of both monsoons "carried off half the population". For the African continent, the situation was quite bad around 1910 with droughts in both East and West Africa. The beginning of the 1980s was the culmination of a few decades of diminishing rainfall.

The new dimension is the amplitude and frequency of these events. What can be done to improve water security and to cater for a growing and more complex demand for water?

\section{Will water take care of itself?}

The late Mr. B.B. Vohra, who was a forceful Joint Secretary, Ministry of Agriculture in India in the 1980s and an outspoken proponent of improved management of both water and land resources, used to say "...if you take care of the soil, water will take care of itself". His argument was that the policies and practices that followed the introduction of the Green Revolution in the mid 1960s overlooked the close links between land and water. For the irrigated agriculture, this omission is serious. For the rain fed systems that make up the major part of the agricultural sector, it is devastating. Without proper land and soil management practices, there is a high risk that only a small share of the rainfall will be harnessed in situ, i.e. infiltrate through the land surface. In the absence of these measures, agricultural droughts and crop failures are obvious. 


\section{Efficient use of the rains}

We are used to talk about the efficiency of the use and allocation of water stored in reservoirs and other impoundments. It is equally relevant and perhaps smarter to think in terms of the efficiency of the rains. The fraction of the rainfall that is impounded may be high in individual rivers but in total, it is around 5\%. Similarly, the fraction available for productive transpiration, i.e. the green water resource is generally low, often less than $30 \%$ but varies significantly between agro-ecological systems and climatic zones. Arrangements for (local) rain water harvesting and storage, and a combination of soil and water conservation practices like low tillage, ripping of the soil surface to allow water to infiltrate and organic matter to build up for improved water holding capacity are among the measures that are often proposed (Molden et al. 2009; Rockström et al. 2009).

\section{Storing water or food?}

But there are no short cuts to progress, that is, on a grand scale. If there were, they had already been exploited. Practical and logistical challenges are significant to harness a larger fraction of an erratic rainfall and to store it over prolonged periods of time. In many cases it would make better sense to store the surplus of food produced during years when conditions are favorable. Based on field studies in northern Tanzania, Enfors (2009) shows that yields are most often low but, occasionally, bumper harvests occur. The buffers that could have been built during fortunate years are, however, lost due to poor storage. Similarly, the possibilities to sell a surplus or to cultivate crops for the market due to inefficient transport and uncertain markets are practically nil.

\section{Who and what will drive development?}

The potential to increase production and productivity in agriculture in large parts of the developing world is often highlighted but also the tremendous challenges involved. Water plays a central role in this regard. Prospects of reducing food insecurity among a deplorable high proportion of the population, for instance, in sub-Saharan Africa are obviously a poor driver of development. Crucial questions are: "who will be prepared and able to increase effort for an uncertain outcome? Will the young generation accept the toil, uncertainties and low pay associated with food production? Are the Governments prepared to spur agricultural growth and if so, what kind of development?" In a book just published, it is argued that the commercial agriculture in the Africa Guinea Savannah Zone is a 'sleeping giant' (Morris et al. 2009). It is argued that vast tracts of lands, about 400 million hectares in 25 countries, are largely unexploited but could be used for producing commodities that could compete effectively on regional and global markets. The book provides a fresh look at the challenges and opportunities. But will water be enough for both food and commercial commodities, for other sectors and how will social issues including equity and environmental challenges be dealt with?

Variability of rainfall and the frequency and duration of dry-spells is a huge problem in semi-arid regions, including the Guinea Savannah Zone. Under current conditions, small farmers face high risks, uncertainties are quite high, the incentives and supporting institutions are insufficient and a vicious circle prevails. But there are examples to show that, with the right institutions, crops, training/extension and market channels, growth in the agricultural sector is conceivable. On what scale and in what time perspective cannot be realistically assessed.

\section{Appendix}

Widespread flooding, often blamed upon deforestation in the upstream catchment, affected 170,000 people in eastern Aceh province, Indonesia in 2006. Over 100 people were confirmed dead. These floods happen every wet season. Traditional wooden buildings, on stilts as in the photo, cope much better than new concrete ones built at ground level which, however, are associated with progress. As the colour of the water indicates, the heavy rains cause erosion and water quality is affected. Photo: Alastair Morrison, SIWI. 


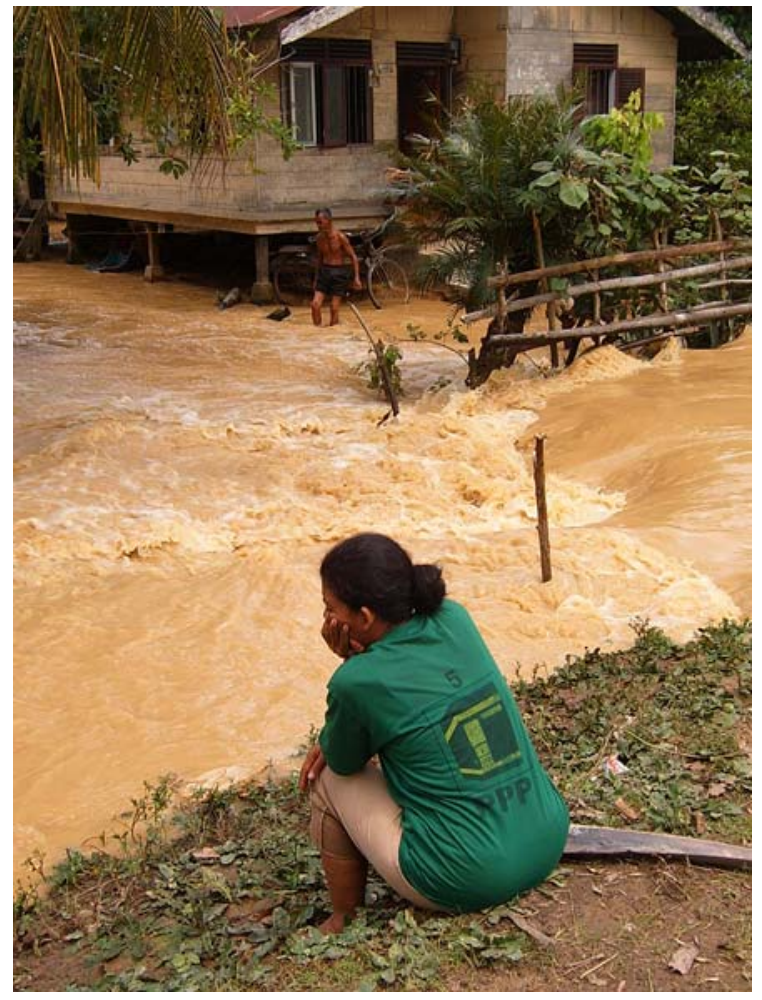

The photo, from 2003, shows a dry channel from Bhavani Sagar Reservoir, Tamil Nadu, India (dam built 1947-1952, i.e. just after Independence during the period when Mr. Jawaharlal Nehru was the Prime Minister). Due to a much below average rainfall during three years, 2001-2003, the release of water for irrigation was reduced significantly and progressively; In 2001/02 it was less than $600 \mathrm{Mm}^{3}$, in 2002/
03 it was about $200 \mathrm{Mm}^{3}$, and 2003/04 it was about $50 \mathrm{Mm}^{3}$. These figures may be compared with the releases that were planned for. A Plan from 1946 assumed a release $650 \mathrm{Mm}^{3}$ annually. In a latter Plan, from 1964, the command area had increased and cropping pattern changed, which lead to a requirement of $1,100 \mathrm{Mm}^{3}$. The photo also shows that perennial vegetation is not affected nor the industry in the back of the photo. Photo: Jan Lundqvist, SIWI.

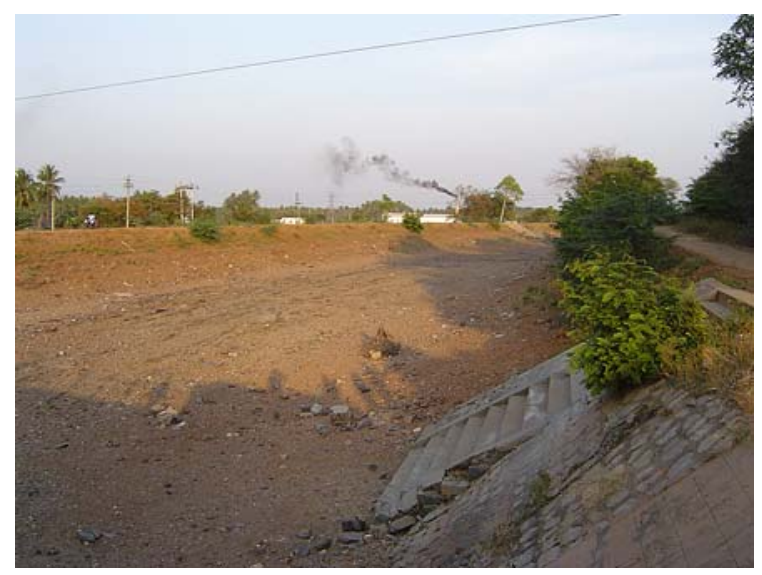

The diagramme illustrates the variation of the flow of water in Bhavani River, Tamil Nadu, India at the site of the Bhavani Sagar Dam. Apart from variation in rainfall, the variation in river flow at this measurement station may be attributed to changes in land use in upstream locations, addition of a number of dams/reservoirs (mainly for hydropower

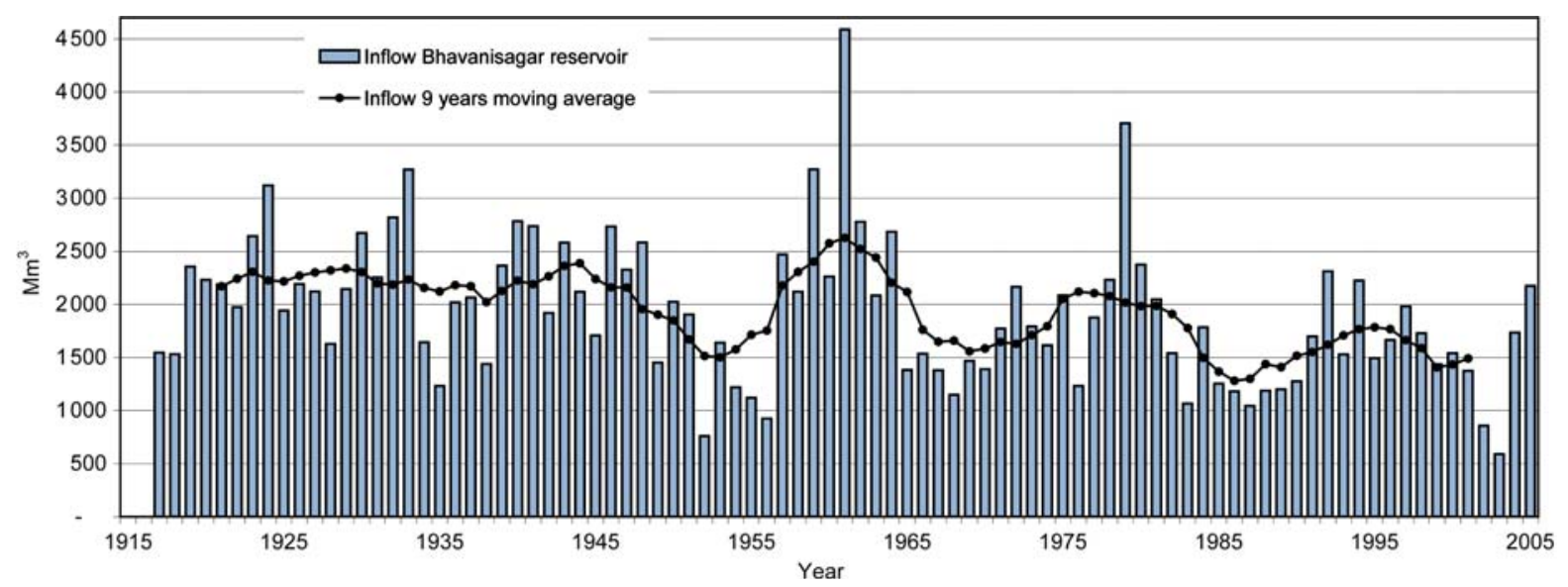


generation) with increased area for evaporation and abstractions from the river, mainly for agriculture. Diagramme: Mats Lannerstad.

\section{References}

Enfors E (2009) Traps and transformations. Exploring the potential of water system innovations in dryland subSaharan Africa. Doctoral Thesis in Natural Resource Management, Department of Systems Ecology, Stockholm University
Lannerstad M (2009) Water realities and development trajectories. Global and local agricultural production dynamics. $\mathrm{PhD}$ thesis, Linköping studies in arts and science. No. 475

Molden D, Oweis T, Steduto P, Bindraban P, Hanja M, Kinje J (2009) Improving agricultural water productivity: between optimism and caution. Agricult Water Manage (in press)

Morris M, Binswanger-Mhkize HP, Byerlee D (2009) Awakening Africa's sleeping giant: prospects for commercial agriculture in the guinea Savannah zone and beyond. The World Bank, Washington, DC

Rockström J, Kaumbutho P, Mwalley J, Nzabi AW, Temesgen M, Mawenya L, Barron J, Mutua J, Damgaard-Larsen S (2009) Conservation farming strategies in East and Southern Africa: yields and rainwater productivity from on-farm action research. Soil Tillage Res 103:23-32 